\title{
Peroxisome proliferator-activated receptor ligands regulate lipid content, metabolism, and composition in fetal lungs of diabetic rats
}

\author{
M Kurtz', E Capobianco', V Careaga ${ }^{2}$, N Martinez', M B Mazzucco', M Maier ${ }^{2}$ \\ and A Jawerbaum ${ }^{1}$ \\ 1'Laboratory of Reproduction and Metabolism, CEFyBO-CONICET, School of Medicine and ${ }^{2}$ UMYMFOR \\ (CONICET-UBA), Department of Organic Chemistry, School of Exact and Natural Sciences, University of \\ Buenos Aires, Buenos Aires, Argentina
}

Correspondence should be addressed to A Jawerbaum

Email

a.jawerbaum@gmail.com

\begin{abstract}
Maternal diabetes impairs fetal lung development. Peroxisome proliferator-activated receptors (PPARs) are ligand-activated transcription factors relevant in lipid homeostasis and lung development. This study aims to evaluate the effect of in vivo activation of PPARs on lipid homeostasis in fetal lungs of diabetic rats. To this end, we studied lipid concentrations, expression of lipid metabolizing enzymes and fatty acid composition in fetal lungs of control and diabetic rats $i)$ after injections of the fetuses with Leukotriene $B_{4}$ (LTB LPPAR $_{4}$ ligand) or 15 deoxy $\Delta^{12,14}$ prostaglandin $\mathrm{J}_{2}\left(15 \mathrm{dPGJ} \mathrm{J}_{2}\right.$, PPAR $\gamma$ ligand) and ii) fed during pregnancy with $6 \%$ olive oil- or $6 \%$ safflower oil-supplemented diets, enriched with PPAR ligands were studied. Maternal diabetes increased triglyceride concentrations and decreased expression of lipid-oxidizing enzymes in fetal lungs of diabetic rats, an expression further decreased by $\mathrm{LTB}_{4}$ and partially restored by $15 \mathrm{dPGJ}_{2}$ in lungs of male fetuses in the diabetic group. In lungs of female fetuses in the diabetic group, maternal diets enriched with olive oil increased triglyceride concentrations and fatty acid synthase expression, while those enriched with safflower oil increased triglyceride concentrations and fatty acid transporter expression. Both olive oil- and safflower oil-supplemented diets decreased cholesterol and cholesteryl ester concentrations and increased the expression of the reverse cholesterol transporter ATP-binding cassette $A 1$ in fetal lungs of female fetuses of diabetic rats. In fetal lungs of control and diabetic rats, the proportion of polyunsaturated fatty acids increased with the maternal diets enriched with olive and safflower oils. Our results revealed important changes in lipid metabolism in fetal lungs of diabetic rats, and in the ability of PPAR ligands to modulate the composition of lipid species relevant in the lung during the perinatal period.
\end{abstract}




\section{Introduction}

Diabetes during pregnancy impairs fetal development, increases fetal morbidity and mortality, and leads to adverse consequences that are evident in the offspring during the perinatal and adult stages (Weindling 2009, Simeoni \& Barker 2009, Ali \& Dornhorst 2011). Both glucose and lipid metabolic substrates transferred in excess from maternal circulation into the fetuses have been involved in the generation of a proinflammatory environment that challenges the development of the fetal organs (Herrera \& Ortega-Senovilla 2010, Lappas et al. 2011, Higa \& Jawerbaum 2013). In the fetal lung, the effect of maternal diabetes is evidenced by structural alterations (Koskinen et al. 2012), delayed pulmonary maturation (Piper 2002), altered production of surfactant proteins and lipids (Bourbon \& Farrell 1985, Trevino-Alanis et al. 2009), and increased pro-oxidative and proinflammatory pathways (Koskinen et al. 2010, Kurtz et al. 2012, Milla \& Zirbes 2012).

Peroxisome proliferator-activated receptors (PPARs) are ligand-activated transcription factors that regulate the expression of target genes involved in lipid homeostasis and in antioxidant and anti-inflammatory processes (Wahli \& Michalik 2012). Endogenous PPAR ligands are certain lipids and lipid derivatives such as unsaturated fatty acids and eicosanoids, capable of activating one or more PPAR isoforms (Hihi et al. 2002). Indeed, the three PPAR isotypes, named PPAR $\alpha$, PPAR $\gamma$, and PPAR $\delta$, can be activated by oleic acid, a monounsaturated fatty acid present in increased concentrations in olive oil, and by linoleic acid, a polyunsaturated fatty acid (PUFA) present in increased concentrations in safflower oil (Hihi et al. 2002). Linoleic acid is an essential fatty acid that leads to the formation of arachidonic acid, a substrate needed for the formation of prostaglandins and leukotrienes. 15 Deoxy $\Delta^{12,14}$ prostaglandin $\mathrm{J}_{2}\left(15 \mathrm{dPGJ}_{2}\right)$ is an endogenous ligand of PPAR $\gamma$ that possesses potent antiinflammatory effects (Scher \& Pillinger 2005). Indeed, PPAR $\gamma$ activation can reduce nitric oxide production and matrix metalloproteinases overactivity, markers of a proinflammatory state, in different tissues, including the lung and the placenta (Jawerbaum et al. 2004, Pustovrh et al. 2009, Wagner et al. 2012). PPAR $\gamma$ is also involved in the differentiation of lipid-laden lung fibroblasts, cells that incorporate and accumulate lipids for further provision of lipids to the alveolar type II cells, which produce the surfactant lipids (Chen et al. 1998, Rehan \& Torday 2012).

On the other hand, leukotriene $\mathrm{B}_{4}\left(\mathrm{LTB}_{4}\right)$ is an endogenous ligand of PPAR $\alpha$, a PPAR isotype clearly involved in the oxidation of lipids in metabolic tissues
(Lefebvre et al. 2006, Narala et al. 2010). In diabetic pregnancies, PPAR $\alpha$ activation negatively regulates lipid content in the fetal liver and the placenta (Martinez et al. $2011 a, b)$. In a recent study, we have found that both administration of $\mathrm{LTB}_{4}$ to fetuses and maternal diets supplemented with $6 \%$ olive oil or $6 \%$ safflower oil (enriched in unsaturated fatty acids that activate the three PPAR isotypes) prevent overproduction of nitric oxide, an excess involved in the induction of a proinflammatory environment in the lungs of fetuses of diabetic rats (Kurtz et al. 2012). Indeed, these PPAR ligands provided by the enriched diets are efficiently transferred to the fetus from the maternal circulation and lead to the regulation of antioxidant, anti-inflammatory, and lipid metabolic pathways in the fetus and the placenta (Jawerbaum \& Capobianco 2011, Martinez et al. 2012).

As lipid content and composition are relevant in the lung in the perinatal period and may be regulated by PPARs, the aims of this work were to analyze lipid content and $\operatorname{PPAR} \alpha$ and PPAR $\gamma$ concentrations in the lungs of fetuses of diabetic rats at term gestation, and address whether in vivo PPAR activation changes lipid content, expression of lipid transporters and metabolizing enzymes and fatty acid composition in the fetal lung. To this end, we addressed the effect of injections of the fetus with the PPAR $\alpha$ ligand $\mathrm{LTB}_{4}$ and the PPAR $\gamma$ ligand $15 \mathrm{dPGJ}_{2}$ on the expression of lipid-oxidizing enzymes in the lungs of fetuses of control and diabetic rats and evaluated the effect of dietary maternal treatments enriched in either $6 \%$ olive oil or $6 \%$ safflower oil on lipid content and on the expression of different PPAR-targeted enzymes involved in lipid metabolism in the lungs of fetuses of control and diabetic rats. Studies were carried out in both male and female fetuses, considering the sex differences evidenced in maturation and signaling pathways in the lung and in lung perinatal diseases (Carey et al. 2007, Seaborn et al. 2010).

\section{Materials and methods}

\section{Animals}

Albino Wistar rats bred in our animal facility were provided with commercial rat chow (Asociación Cooperativa Argentina, Buenos Aires, Argentina) and allowed to feed ad libitum. To induce diabetes, at 2 days of age, neonates received injections of streptozotocin (90 mg/kg, s.c.; Sigma-Aldrich) diluted in citrate buffer (0.05 M, pH 4.5; Sigma-Aldrich), as described previously

Published by Bioscientifica Ltd 
(Jawerbaum \& White 2010, Martinez et al. 2011b). Control animals received injections of citrate buffer alone. The diabetic state was confirmed in 2-month-old rats before mating. The rats were considered diabetic when they presented fasting glycemia values higher than $130 \mathrm{mg} / \mathrm{dl}$. The guidelines for the care and use of animals approved by the local institution were followed, according to the Principles of Laboratory Animal Care (NIH publication number 85-23, revised 1985, http://grants1.nih.gov/ grants/olaw/references/phspol.htm).

\section{Experimental design}

Control and diabetic female rats were mated with control males. The presence of sperm cells in vaginal smears confirmed the first day of pregnancy (gestational day 1 (GD1)). On this day, both control and diabetic animals were randomized into three different groups: Group 1, non-treated animals; Group 2, animals whose fetuses were treated in vivo with either the PPAR $\alpha$ ligand $\mathrm{LTB}_{4}$ or the PPAR $\gamma$ ligand $15 \mathrm{dPGJ}_{2}$; and Group 3, animals fed with diets supplemented with $6 \%$ olive oil or $6 \%$ safflower oil, enriched in natural PPAR activators, from GD1 to GD21.

In Group 1, control $(n=9)$ and diabetic $(n=9)$ female rats were killed on GD21 and the lungs were explanted and preserved as described later.

In Group 2, the fetuses were treated in vivo with $\mathrm{LTB}_{4}$ or $15 \mathrm{dPGJ}_{2}$ or with vehicle alone on GD19, GD20, and GD21, as described previously (Kurtz et al. 2012). For this purpose, on GD19, GD20, and GD21, the pregnant animals were anesthetized in a $\mathrm{CO}_{2}$ chamber and a slight anesthesia was maintained with ether vapors. An abdominal incision was performed and the left horn of the uterus was exposed. The animals which had five to seven fetuses in their left uterine horn were used. The fetuses were numbered from the ovary and alternate fetuses received subcutaneous injections on their backs through the uterine wall of with i) $\mathrm{LTB}_{4}(0.1 \mathrm{nmol} /$ fetus dissolved in vehicle; Cayman Chemical Co., Ann Arbor, MI, USA) or vehicle (0.3 $\mu 1$ ethanol/fetus, dissolved in saline solution) ( $n=9$ rats) and ii) with $15 \mathrm{dPGJ}_{2}(2 \mathrm{nmol} /$ fetus, dissolved in vehicle; Cayman Chemical Co.) or vehicle $(0.3 \mu \mathrm{l}$ ethanol/fetus, dissolved in saline solution) ( $n=9$ rats). After administration, the left uterine horn was carefully introduced into the abdominal cavity and the abdominal muscle layer and the skin layer were independently sewn. The entire surgery lasted less than $10 \mathrm{~min}$ and the animals were completely recovered after $15 \mathrm{~min}$. At $3 \mathrm{~h}$ after the last injection on GD21, the animals were killed and the fetal lungs were explanted and preserved as described below.
In Group 3, control and diabetic mothers were fed from GD1 to GD21, with diets enriched in unsaturated fatty acids that activate PPARs: $6 \%$ olive oil $(354 \%$ enriched in oleic acid) and 6\% safflower oil $(226 \%$ enriched in linoleic acid) ( $n=9$ in each experimental group), as previously described (Martinez et al. 2012). The composition of this diet is presented in Table 1. On GD21, animals were killed and the fetal lungs were explanted and preserved as described below.

In all groups, animals were killed through decapitation. Maternal and fetal blood was collected in heparinized tubes and plasma was preserved at $-80^{\circ} \mathrm{C}$. Under a stereomicroscope, the sex of fetuses was determined and their lungs were explanted. Lungs of male and female fetuses were randomly selected and either preserved at $-80^{\circ} \mathrm{C}$ for further analysis of lipid content and fatty acid composition or preserved in RNA stabilization solution (RNAlater, Invitrogen) for further evaluation of the expression of enzymes and transporters involved in lipid metabolism.

\section{Blood and plasma measurements}

Glycemic values were measured using Accu-Chek reagent strips and a glucometer Accu-Chek (Bayer Diagnostics) within blood obtained from the tail vein of the mothers.

Maternal and fetal glycemia and triglyceridemia were measured in plasma using an enzymatic colorimetric commercial kit (Wiener Lab., Rosario, Argentina). Plasma from all female and male fetuses in each litter was pooled for this analysis.

Table 1 Composition of diet. Reprinted from Martinez N, Sosa M, Higa R, Fornes D, Capobianco E \& Jawerbaum A 2012 Dietary treatments enriched in olive and safflower oils regulate seric and placental matrix metalloproteinases in maternal diabetes. Placenta 33 8-16, with permission from Elsevier

\begin{tabular}{|c|c|c|c|}
\hline & $\begin{array}{l}\text { Standard } \\
\text { diet }\end{array}$ & $\begin{array}{l}\text { Standard diet } \\
\text { supplemented } \\
\text { with } 6 \% \\
\text { olive oil }\end{array}$ & $\begin{array}{l}\text { Standard diet } \\
\text { supplemented } \\
\text { with } 6 \% \\
\text { safflower oil }\end{array}$ \\
\hline $\begin{array}{l}\text { Carbohydrates } \\
(\mathrm{g} / 100 \mathrm{~g})\end{array}$ & 50 & 48 & 47 \\
\hline Proteins $(\mathrm{g} / 100 \mathrm{~g})$ & 25 & 24 & 23 \\
\hline Fat $(\mathrm{g} / 100 \mathrm{~g})$ & 5 & 11 & 11 \\
\hline Calories (kcal \%) & 324 & 340 & 345 \\
\hline \multicolumn{4}{|l|}{$\begin{array}{l}\text { Major fatty acid } \\
\text { content }(\mathrm{g} / 100 \mathrm{~g})\end{array}$} \\
\hline C16:0 palmitic acid & 0.58 & 1.55 & 0.97 \\
\hline C18:0 estearic acid & 0.16 & 0.26 & 0.25 \\
\hline C18:1 oleic acid & 1.27 & 5.77 & 1.81 \\
\hline C18:2 linoleic acid & 1.99 & 2.41 & 6.49 \\
\hline C18:3 linolenic acid & 0.73 & 0.57 & 0.55 \\
\hline
\end{tabular}

Published by Bioscientifica Ltd 


\section{Lipid content measurements}

Lungs of one female and one male fetus from each rat group were each homogenized in $1000 \mu \mathrm{lBS}$ and protein content in the homogenates was measured by the Bradford assay. Tissue lipids were extracted from $500 \mu \mathrm{l}$ of each homogenate by three rounds of organic extraction in methanol:chloroform (2:1), following the method of Bligh \& Dyer, as previously performed (Martinez et al. 2011b). The lipids extracted (equivalent to $400 \mu \mathrm{g}$ of protein) were developed by thin layer chromatography on $0.2 \mathrm{~mm}$ silica gel plates (Merck), using hexane:ether:acetic acid (80:20:2, $\mathrm{v}: \mathrm{v}: \mathrm{v})$ as the developing solvent mixture. Lipid species were stained with iodine vapors, identified and quantified by comparison with known amounts of standards on the same plate, and analyzed densitometrically with the Image J Software (Bethesda, MD, USA).

\section{Expression of enzymes and transporters involved in lipid metabolism}

Lung RNA was extracted from one female and one male fetus from each rat group for the evaluation of gene expression of acyl CoA oxidase (ACO), carnitine palmitoyltransferase 1 (CPT1), fatty acid synthase (FAS), fatty acid transporter (FAT), and ATP-binding cassette A1 (ABCA1) by RT-PCR, a semiquantitative method, as previously determined (Kurtz et al. 2012). Fetal lung RNA was extracted with Tri reagent (Genbiotech, Buenos Aires, Argentina) in accordance with the manufacturer's instructions. cDNA was synthesized by incubating $1 \mu \mathrm{g}$ of extracted RNA in a first-strand buffer containing MMLV enzyme (Promega), random primer hexamers, and each of all four dNTPs (Invitrogen), in accordance with the MMLV manufacturer's instructions. cDNA $(2 \mu \mathrm{l})$ was used to perform the amplification in $25 \mu \mathrm{l}$ reaction buffer containing dNTPs, magnesium chloride solution, Taq polymerase (GoTaq Polymerase; Promega), and each specific primer, in accordance with the Taq polymerase manufacturer's instructions.

Primers for ACO were forward: 5'-CCAATCACGCAATAGTTCTGG- $3^{\prime}$ and reverse: $5^{\prime}$-CGCTGTATCGTATGGCGAT-3', whose amplification product is a 363-bp fragment (Lillycrop et al. 2005). Primers for CPT1 were forward: 5'-TATCGTCGCACATTAGACCGT-3' and reverse: 5'-CATCTATGACCTCCTGGCACT-3', whose amplification product is a 715-bp fragment (Cheng et al. 2004). Primers for FAS were forward: $5^{\prime}$-CTTGGGTGCCGATTACAACC-3' and reverse: 5'-GCCCTCCCGTACACTCACTC-3', whose amplification product is a 163-bp fragment (Salas et al. 2007). Primers for FAT were forward: $5^{\prime}$-CTCTGACATTTGCAGGTCCA-3' and reverse: 5'-CACAGGCTTTCCTTCTTTGC-3', whose amplification product is a 214-bp fragment (designed using Primer 3 Software, http://bioinfo.ut.ee/primer3-0.4.0/primer3). Primers for ABCA1 were forward: 5'-CAGGCTGATGTCAGTCTCCA- $3^{\prime}$ and reverse: 5'-GGCTTCAGGATGTCCATGTT-3', whose amplification product is a 194-bp fragment (Kobayashi et al. 2011). The primers for the ribosomal protein L30, used as an internal control were forward: 5'-CCATCTTGGCGTCTGATCTT-3' and reverse: 5'-GGCGAGGATAACCAATTTC- $3^{\prime}$, whose amplification product is a 201-bp fragment, (Primer 3 Software). The initial conditions for the reaction were $95^{\circ} \mathrm{C}$ for $5 \mathrm{~min}$, followed by 34 cycles for ACO, 34 cycles for CPT1, 32 cycles for FAS, 29 cycles for FAT, 28 cycles for ABCA1, and 25 cycles for L30. Each cycle consisted of denaturation at $95^{\circ} \mathrm{C}$ for $15 \mathrm{~s}$, primer annealing at $58{ }^{\circ} \mathrm{C}$ for $30 \mathrm{~s}$, and extension at $72{ }^{\circ} \mathrm{C}$ for $15 \mathrm{~s}$. The resulting products were separated on a $2 \%$ agarose gel and stained with syber safe (Invitrogen). The images were taken with an ImageQuant spectrophotometer (GE Healthcare, Little Chalfont, Buckinghamshire, UK) and the density of the bands was quantified with the Image J Software and normalized to L30.

\section{Fatty acid composition of tissue lipids}

Fatty acid methyl esters (FAME) of lung lipids extracted from one female and one male fetus from each rat group were prepared by reaction with $5 \% \mathrm{HCl}$ in methanol at $70{ }^{\circ} \mathrm{C}$ for $2 \mathrm{~h}$. After cooling, water was added and FAME were extracted with chloroform. FAME were analyzed by gas chromatography-mass spectrometry on a Shimadzu GCMS-QP5050 A (Shimadzu Corporation, Kyoto, Japan) as previously described (Careaga et al. 2013). FAME were also analyzed by gas chromatography on a Thermo Focus CG chromatograph equipped with a flame ionization detector and a DB225 cross-linked methyl silicone fused silica capillary column $(15 \mathrm{~m} \times 0.25 \mathrm{~mm}$ internal diameter, $0.25 \mu \mathrm{m}$ thickness; Agilent Corporation, Santa Clara, CA, USA). Nitrogen was the carrier gas. Both injector and detector temperatures were set at $280^{\circ} \mathrm{C}$. Column temperature was programed to increase from 37 to $195^{\circ} \mathrm{C}$ at a rate of $24^{\circ} \mathrm{C} / \mathrm{min}$ then remain stable at $195^{\circ} \mathrm{C}$ for $1 \mathrm{~min}$, then increase at a rate of $3{ }^{\circ} \mathrm{C} / \mathrm{min}$ up to $205^{\circ} \mathrm{C}$ and remain at this temperature for $1 \mathrm{~min}$, then increase at a rate of $8{ }^{\circ} \mathrm{C} / \mathrm{min}$ up to $230^{\circ} \mathrm{C} / \mathrm{min}$ and remain stable at $230^{\circ} \mathrm{C}$ for $35 \mathrm{~min}$. Individual components were identified using mass spectral data and by comparing retention time data with those obtained for authentic laboratory standards (Sigma-Aldrich Co.). Quantitation was done by comparing the percentage area of each FAME peak on the chromatogram with that of the internal standard

Published by Bioscientifica Ltd 
of known weight (nonadecanoate methyl ester; SigmaAldrich Co.) and expressed as percentage of total fatty acids.

\section{Immunohistochemistry}

$\operatorname{PPAR} \alpha$ and PPAR $\gamma$ immunolocalization was evaluated in lung sections from one female and one male fetus from each rat, as previously performed on other tissues (Capobianco et al. 2005). All sections were processed simultaneously under identical conditions. Briefly, lung tissues were fixed with $4 \%$ paraformaldehyde and then dehydrated and embedded in paraffin. Sections of $5 \mathrm{~mm}$-thickness were deparaffinized and hydrated in xylene and a series of graded ethanol solutions. Antigen retrieval was performed by microwave heating these sections in trisodium citrate buffer and endogenous peroxidase was blocked with $0.3 \%$ $\mathrm{H}_{2} \mathrm{O}_{2}$ in PBS. The sections were incubated in a humidified chamber overnight with either a rabbit anti-PPAR $\alpha$ antibody (1:300, Cayman Chemical Co.) or a rabbit anti-PPAR $\gamma$ antibody (1:50, Santa Cruz Biotechnology). Primary antibodies were diluted in PBS buffer with 0.05\% Tween-20 (PBS-T) with 1\% BSA. Negative controls were performed by omitting the primary antibody. Incubations were performed with biotinylated goat anti-rabbit antibody (1:200 in PBS-T, Vector Laboratories, Burlingame, CA, USA) followed by incubation with an avidin-biotin complex. Staining was visualized by adding 40\% 3,30-diaminobenzidine tetrahydrochloride chromogen-buffer plus $0.02 \%(\mathrm{v} / \mathrm{v})$ $\mathrm{H}_{2} \mathrm{O}_{2}$ in $0.05 \mathrm{M}$ Tris ( $\mathrm{pH}$ 7.6); positive staining appeared as a dark brown color. The sections were examined under light microscopy by two skilled blinded observers. Immunoreactivity intensity was quantified using the ImageProPlus Software (Media Cybernetics Inc. Rockville, MD, USA). Data are shown as relative to a value of 1 assigned to the mean value for each PPAR in female tissues from control rats.

\section{Statistical analysis}

Data are presented as the mean \pm s.E.M. Groups were compared by Student's $t$-test or two-way ANOVA in conjunction with Bonferroni's test where appropriate. A $P$ value $<0.05$ was considered statistically significant.

\section{Results}

\section{Maternal diabetes leads to lipid overaccumulation and} altered PPAR $\alpha$ and PPAR $\gamma$ concentrations in the fetal lung

Maternal diabetes led to increases in glycemia in both the mothers (control, $93 \pm 7$ and diabetic, $215 \pm 23 \mathrm{mg} / \mathrm{dl}$;
$P<0.001$ ) and the fetuses (fetuses of control mothers, $46 \pm 4$ and fetuses of diabetic mothers, $147 \pm 10 \mathrm{mg} / \mathrm{dl}$; $P<0.001)$. Also triglyceridemia was increased in both the mothers (control, $2.1 \pm 0.3$ and diabetic, $4.1 \pm 0.3 \mathrm{~g} / \mathrm{l}$; $P<0.01$ ) and the fetuses (fetuses of control mothers, $0.53 \pm 0.07$ and fetuses of diabetic mothers, $0.90 \pm$ $0.07 \mathrm{~g} / \mathrm{l} ; P<0.01)$. These data correspond to all male and female fetuses of control $(n=9)$ and diabetic $(n=9)$ rats as no sex differences were observed.

The analysis of fetal lung lipid concentrations showed increased triglyceride concentrations $(P<0.01)$ and no changes in the concentrations of phospholipids, cholesterol, and cholesteryl esters in lungs of female fetuses in the diabetic group compared with controls, and increased triglyceride $(P<0.001)$ and phospoholipid $(P<0.05)$ concentrations and no changes in cholesterol and cholesteryl esters concentrations in the lungs of male fetuses in the diabetic group when compared with controls (Fig. 1A). Together with these changes, decreased expression of ACO and CPT1, rate-limiting enzymes in lipid oxidation, was observed in the lungs of both female and male fetuses in the diabetic groups $(P<0.05)$ when compared with the respective control groups (Fig. 1B and C).

The analysis of PPARs showed that PPAR $\alpha$ concentrations were similar in the lungs of female fetuses and reduced in the lungs of male fetuses in the diabetic group when compared with controls (Fig. 1D, lungs of female fetuses of control mothers: $1 \pm 0.19, n=5$; lungs of female fetuses of diabetic mothers: $1.29 \pm 0.09, n=5$; lungs of male fetuses of control mothers: $0.9 \pm 0.14, n=5$; and lungs of male fetuses of diabetic mothers: $0.47 \pm 0.02$, $n=5 ; \quad P<0.05)$. Similarly, $\operatorname{PPAR} \gamma$ concentrations were similar in the lungs of female fetuses and reduced in the lungs of male fetuses in the diabetic group when compared with controls (Fig. 1E, lungs of female fetuses of control mothers: $1 \pm 0.34, n=5$; lungs of female fetuses of diabetic mothers: $1.37 \pm 0.46, n=5$; lungs of male fetuses of control mothers: $1.19 \pm 0.12, n=5$; and lungs of male fetuses of diabetic mothers: $0.48 \pm 0.11, n=5 ; P<0.01$ ).

\section{Effect of fetal administration of PPAR ligands on the expression of rate-limiting enzymes in lipid oxidation}

Considering the well-known function of PPAR $\alpha$ in the regulation of lipid-oxidizing enzymes in different tissues (Desvergne et al. 2006, Lefebvre et al. 2006) and the decrease in lipid-oxidizing enzymes and overaccumulation of lipids observed in the lungs of fetuses of diabetic rats, we analyzed the in vivo effects of fetal PPAR $\alpha$ activation on the expression of ACO and CPT1 in the lungs of female

Published by Bioscientifica Ltd. 
A Female fetuses
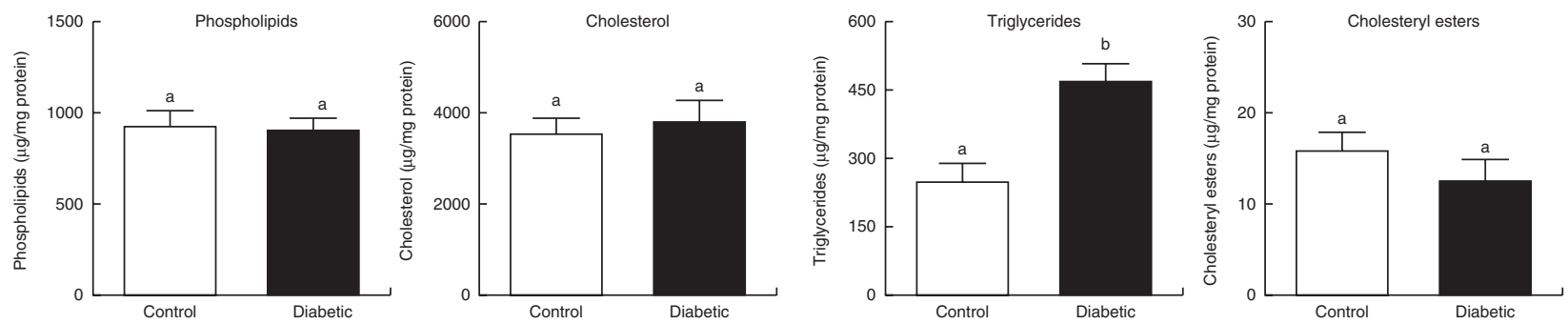

Male fetuses
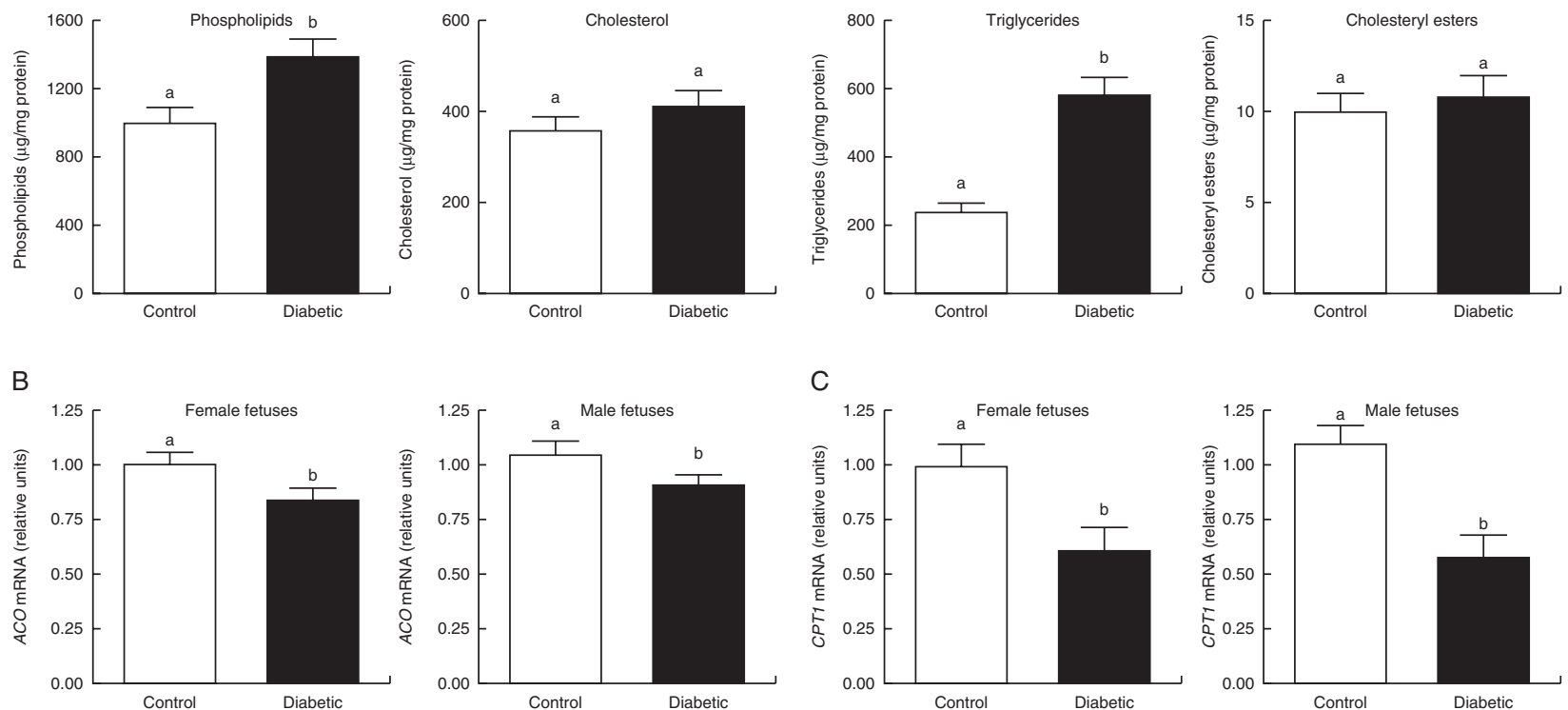

D

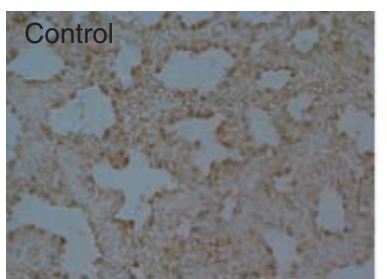

Female fetuses

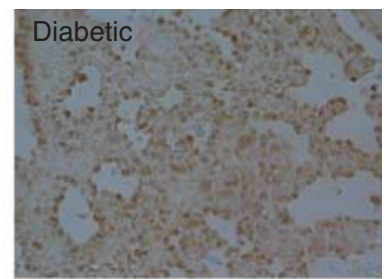

Male fetuses
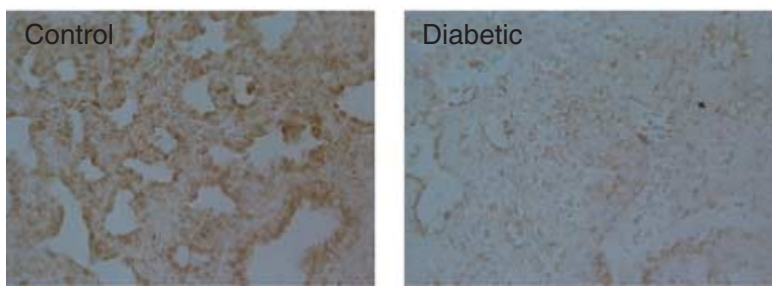

Figure 1

(A) Lipid concentrations, (B) ACO expression, and (C) CPT1 expression in lungs of fetuses of control and diabetic rats. Values represent mean \pm s.E.M., obtained from one female or one male fetus from each pregnant rat, $n=9$ rats in each experimental group. Student's $t$-test was performed. Different letters denote significant differences between groups, $P<0.05$.
C
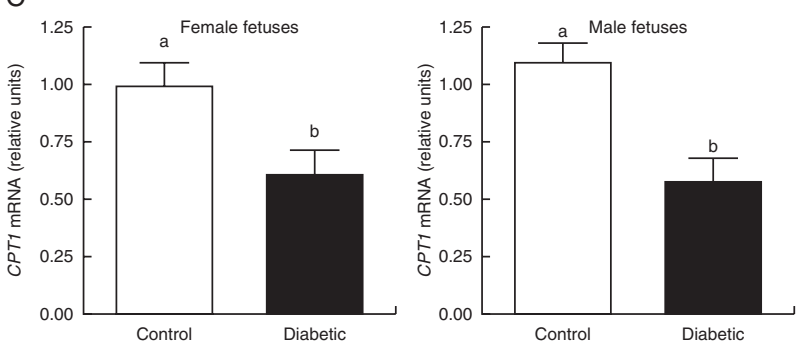

$E$
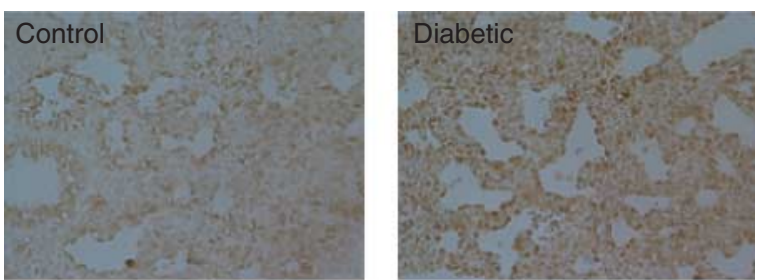

Male fetuses
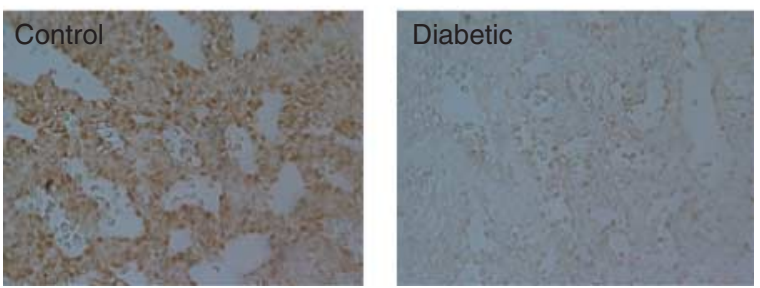

(D) Representative photomicrographs of PPAR $\alpha$ (original magnification, $400 \times$ ) immunodetected with specific anti-PPAR $\alpha$ antibody in lungs of fetuses of control and diabetic rats. (E) Representative photomicrographs of PPAR $\gamma$ (original magnification, $400 \times$ ) immunodetected with specific anti-PPAR $\gamma$ antibody in lungs of fetuses of control and diabetic rats.

Published by Bioscientifica Ltd. 
A

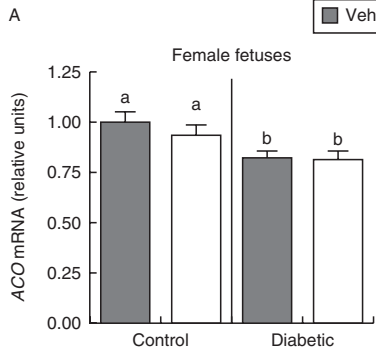

$\square$ Vehicle $\square \mathrm{LTB}_{4}$
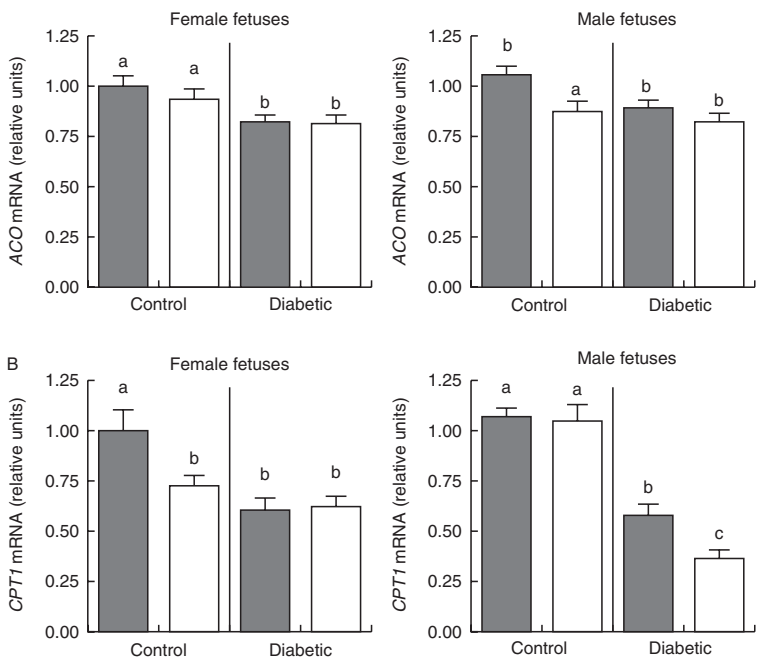

Figure 2

(A) ACO expression and (B) CPT1 expression in lungs of fetuses that had received injections of the PPAR $\alpha$ agonist $\mathrm{LTB}_{4}$ or of vehicle. Values represent mean \pm s.E.M., obtained from one female or one male fetus from each pregnant rat, $n=9$ rats in each experimental group. Two-way ANOVA in conjunction with Bonferroni's test was performed. Different letters denote significant differences between groups, $P<0.05$.

and male fetuses of control and diabetic mothers. For this purpose, fetuses from control and diabetic rats received injections of either $\mathrm{LTB}_{4}(0.1 \mathrm{nmol})$ or vehicle through the uterine wall on GD19, GD20, and GD21, and the fetal plasma and lungs were evaluated on GD21. Glycemia and triglyceridemia were increased in the diabetic fetuses that received $\mathrm{LTB}_{4}$ when compared with the control fetuses that received the same treatment ((glycemia $(\mathrm{mg} / \mathrm{dl})$ : $\mathrm{LTB}_{4}{ }^{-}$ treated fetuses of control mothers, $47 \pm 9$ and $\mathrm{LTB}_{4}$-treated fetuses of diabetic mothers, $136 \pm 10 ; P<0.001)$ and (triglyceridemia $(\mathrm{g} / \mathrm{l}): \mathrm{LTB}_{4}$-treated fetuses of control mothers, $0.60 \pm 0.05$ and $\mathrm{LTB}_{4}$-treated fetuses of diabetic mothers, $0.88 \pm 0.03 \mathrm{~g} / \mathrm{l} ; P<0.01)$ ). These data correspond to all male and female fetuses of control $(n=9)$ and diabetic $(n=9)$ rats, as no sex differences were observed. Thus, we observed that the $\mathrm{LTB}_{4}$-treated fetuses showed the same changes in glycemia and triglyceridemia in control and diabetic groups as untreated fetuses. Fetal administration of $\mathrm{LTB}_{4}$ during on late gestation induced a decrease in ACO expression in lungs of male fetuses $(P<0.05)$ and a decrease in CPT1 expression in lungs of female fetuses $(P<0.01)$ in the control group, and led to a further decrease in CPT1 expression $(P<0.001)$ in the lungs of male fetuses in the diabetic group (Fig. 2).

Considering that PPAR $\alpha$ regulation of ACO and CPT1 in the fetal lung is different from that of metabolic tissues such as the liver and the heart (Desvergne et al. 2006, Lefebvre et al. 2006), we further addressed the ability of the PPAR $\gamma$ ligand $15 \mathrm{dPGJ}_{2}$ to regulate the expression of the evaluated enzymes involved in lipid oxidation. For this purpose, fetuses from control and diabetic rats received injections of either $15 \mathrm{dPGJ}_{2}(2 \mathrm{nmol})$ or vehicle through the uterine wall on GD19, GD20, and GD21, for further evaluation of fetal plasma and lungs on GD21. Glycemia and triglyceridemia were increased in the diabetic fetuses that received $15 \mathrm{dPGJ}_{2}$ when compared with the control fetuses that received the same treatment ((glycemia: $15 \mathrm{dPGJ}_{2}$-treated fetuses of control mothers, $53 \pm 11$ and $15 \mathrm{dPGJ}_{2}$-treated fetuses of diabetic mothers, $158 \pm$ $12 \mathrm{mg} / \mathrm{dl} ; P<0.001$ ) and (triglyceridemia: $15 \mathrm{dPGJ}_{2}$-treated fetuses of control mothers, $0.61 \pm 0.05$ and $15 \mathrm{dPGJ}_{2}$-treated of from diabetic mothers, $0.75 \pm 0.03 \mathrm{~g} / \mathrm{l} ; P<0.05)$ ). These data correspond to all male and female fetuses in each experimental group, obtained from control $(n=9)$ and diabetic $(n=9)$ rats, as no sex differences were observed. Fetal administration of $15 \mathrm{dPGJ}_{2}$ on late gestation induced no changes in ACO or CPT1 expression in the lungs of either female or male fetuses in the control group and in the lungs of female fetuses in the diabetic group. In contrast, fetal administration of $15 \mathrm{dPGJ}_{2}$ induced an increase in ACO and CPT1 expression in the lungs of male fetuses in the diabetic group $(P<0.05$; Fig. 3$)$.

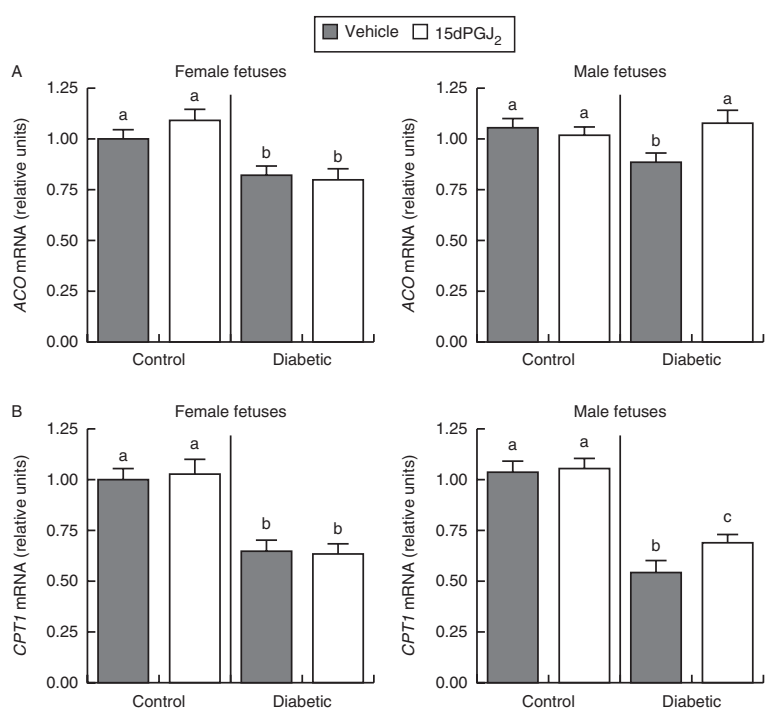

\section{Figure 3}

(A) ACO expression and (B) CPT1 expression in lungs of fetuses that had received injections of the PPAR $\gamma$ agonist $15 \mathrm{dPGJ}_{2}$ or of vehicle. Values represent mean \pm s.E.M., obtained from one female or one male fetus from each pregnant rat, $n=9$ rats in each experimental group. Two-way ANOVA in conjunction with Bonferroni's test was performed. Different letters denote significant differences between groups, $P<0.05$. 


\section{Effect of maternal diets enriched in PPAR ligands on lipid concentrations}

Our previous studies have demonstrated the effects of dietary activation of PPARs on maternal diabetes in different fetal organs (Jawerbaum \& Capobianco 2011, Martinez et al. 2011b) and the ability of these diets to reach the fetal lungs and regulate the expression of PPAR $\alpha$ (Kurtz et al. 2012). Thus, we analyzed lipid composition and the expression of enzymes/transporters involved in lipid metabolism in the lungs of fetuses of control and diabetic rats fed with a $6 \%$ olive-oil-supplemented diet $(354 \%$ enriched in oleic acid) or a $6 \%$ safflower-oil-supplemented diet (226\% enriched in linoleic acid) during pregnancy (GD1-GD21).

Neither the $6 \%$ olive-oil- nor the $6 \%$ safflower-oilsupplemented diets changed fetal glycemia and triglyceridemia in control and diabetic experimental groups when compared with their respective groups fed the standard diet ((control rats: glycemia $(\mathrm{mg} / \mathrm{dl})$ : fetuses of control rats fed: i) the standard diet $42 \pm 12$, ii) the $6 \%$ olive-oilsupplemented diet $47 \pm 10$, and iii) the $6 \%$ safflower-oilsupplemented diet $49 \pm 10$; triglyceridemia $(\mathrm{g} / \mathrm{l})$ : fetuses of control rats fed: i) the standard diet $0.58 \pm 0.05$, ii) the $6 \%$ olive-oil-supplemented diet $0.60 \pm 0.04$, and iii) the $6 \%$ safflower oil-supplemented diet $0.59 \pm 0.06$ ) and (diabetic rats: glycemia $(\mathrm{mg} / \mathrm{dl})$ : fetuses of diabetic rats fed: i) the standard diet $142 \pm 20$, ii) the $6 \%$ olive-oil-supplemented diet $146 \pm 25$, and iii) the $6 \%$ safflower-oil-supplemented diet $128 \pm 26$; triglyceridemia $(\mathrm{g} / \mathrm{l})$ : fetuses of control rats fed: i) the standard diet $1.01 \pm 0.10$, ii) the $6 \%$ olive-oil-supplemented diet $1.10 \pm 0.11$, and iii) the $6 \%$ safflower-oil-supplemented diet $1.05 \pm 0.09)$ ). These data correspond to all male and female fetuses ( $n=9$ rats in each experimental group) as no sex differences were observed. When we analyzed lipid concentrations in the lungs of female and male fetuses of control rats, we found that the maternal supplementation with either the $6 \%$ olive oil- or $6 \%$ safflower oil-supplemented diets did not change the concentrations of the lipids evaluated when compared with the respective control groups fed the standard diet (Fig. 4). In contrast, in the lungs of female fetuses in the diabetic group, triglyceride concentrations were increased $(P<0.05)$, and cholesterol and cholesteryl esters decreased $(P<0.05)$ when the dams were fed with either the $6 \%$ olive-oil- or the $6 \%$ safflower-oil-supplemented diets and related to the diabetic group fed the standard diet (Fig. 4). On the other hand, in the lungs of male fetuses in the diabetic group, the only change observed was an increase in phospholipids when the dams were fed the $6 \%$ olive-oil-supplemented diet and compared with the diabetic group fed the standard diet $(P<0.05$; Fig. 4$)$.

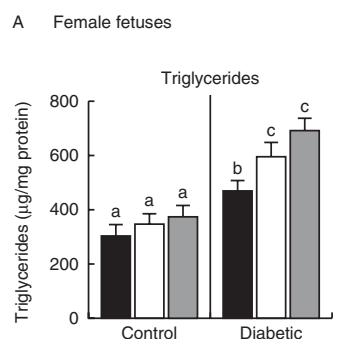

$\square$ Standard diet $\square$ Olive-oil-supplemented diet $\square$ Safflower-oil-supplemented diet

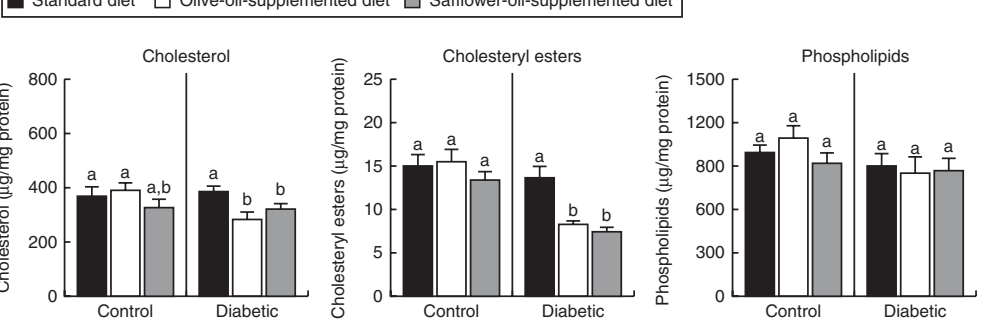

B Male fetuses
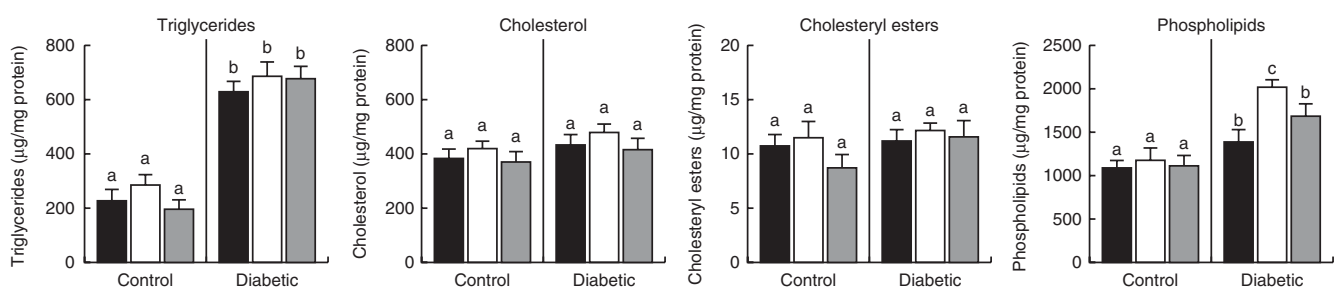

Figure 4

Lipid concentrations in lungs of fetuses of control and diabetic rats fed with a $6 \%$ olive-oil- or a $6 \%$ safflower-oil-supplemented diet during pregnancy. Values represent mean \pm s.E.M., obtained from one female or one male fetus
() 2014 Society for Endocrinology Printed in Great Britain from each pregnant rat, $n=9$ rats in each experimental group. Two-way ANOVA in conjunction with Bonferroni's test was performed. Different letters denote significant differences between groups, $P<0.05$. 
Effect of maternal diets enriched in PPAR ligands on the expression of enzymes/transporters involved in lipid metabolism

Considering the changes evidenced in lipid concentrations in lungs of fetuses of diabetic rats fed with the diets enriched in fatty acids that activate PPARs, and the well-known ability of PPARs to regulate different enzymes and transporters involved in the synthesis and transport of lipids (Desvergne et al. 2006), we analyzed the expression of FAS, FAT, and ABCA1 in lungs of fetuses of control and diabetic rats fed with a $6 \%$ olive-oil- or a $6 \%$ safflower-oilsupplemented diet during pregnancy.

FAS expression was unchanged in lungs of female and male fetuses in the diabetic group fed the standard diet when compared with their respective controls fed the same diet (Fig. 5A). In the control group, FAS expression was unchanged in lungs of female and male fetuses when
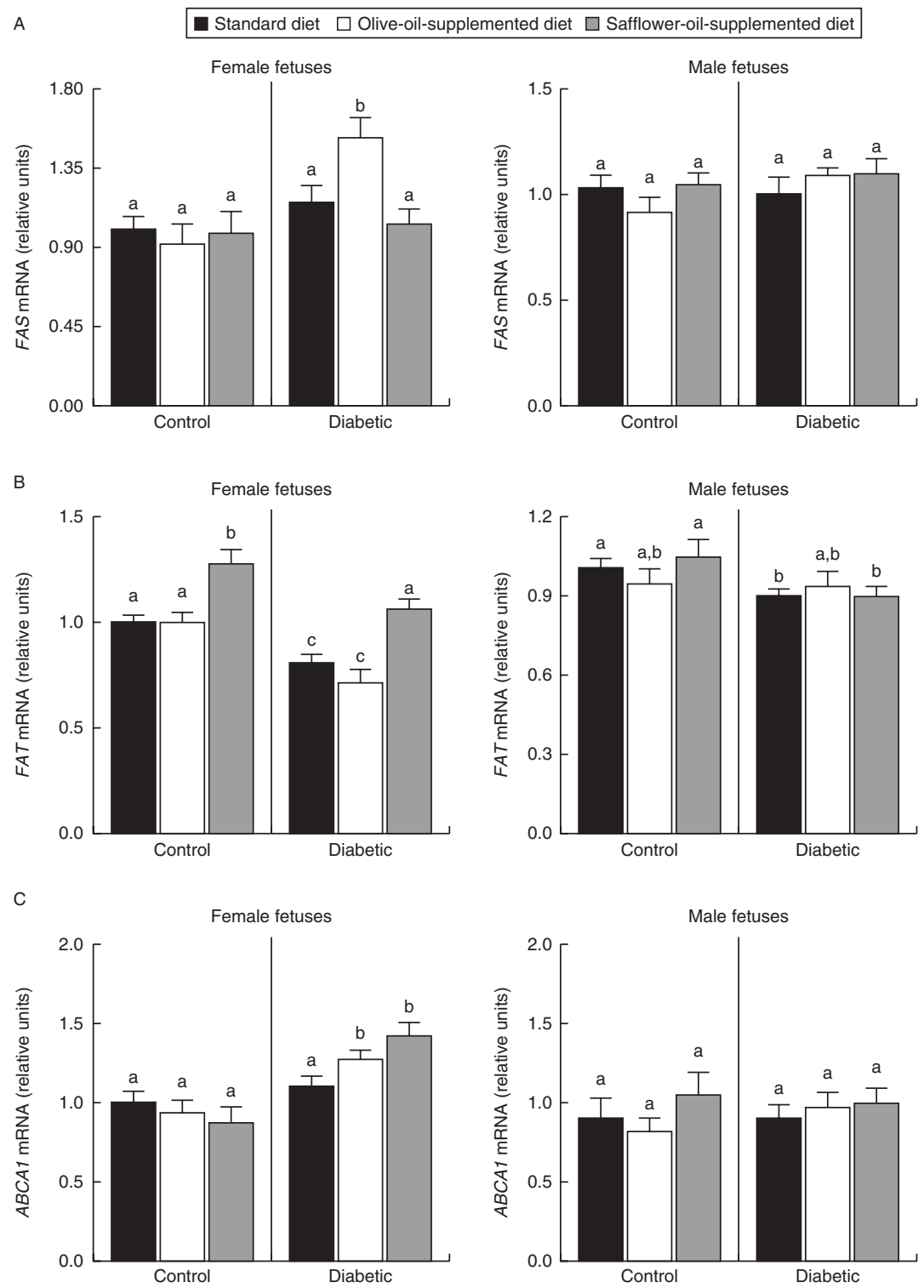

Figure 5

(A) FAS expression, (B) FAT expression, and (C) ABCA1 expression in lungs of fetuses of control and diabetic rats fed with a $6 \%$ olive-oil- or a $6 \%$ safflower-oil-supplemented diet during pregnancy. Values represent mean + S.E.M., obtained from one female or one male fetus from each

pregnant rat, $n=9$ rats in each experimental group. Two-way ANOVA in conjunction with Bonferroni's test was performed. Different letters denote significant differences between groups, $P<0.05$.

Published by Bioscientifica Ltd. 
the animals fed either the $6 \%$ olive-oil- or the $6 \%$ safflower-oil-supplemented diets were compared with control animals fed the standard diet (Fig. 5A). FAS expression was increased in lungs of female fetuses $(P<0.05)$, but unchanged in lungs of male fetuses in the diabetic group fed the $6 \%$ olive-oil-supplemented diet when compared with the diabetic group fed the standard diet (Fig. 5A). FAS expression was also unchanged in lungs of female and male fetuses in the diabetic group fed the $6 \%$ safflower-oil-supplemented diet when compared with the diabetic animals fed the standard diet (Fig. 5A).

FAT expression was decreased in lungs of both female and male fetuses in the diabetic group fed the standard diet when compared with their respective controls fed the same diet $(P<0.05$; Fig. 5B). FAT expression was unchanged in lungs of female fetuses in both the control and diabetic groups fed the $6 \%$ olive oil-supplemented diet when compared with their respective controls fed the standard diet. However, FAT expression was increased in lungs of female fetuses in both the control and diabetic groups fed the $6 \%$ safflower-oil-supplemented diet when respectively compared with the control and diabetic groups fed the standard diet $(P<0.05$; Fig. 5B). FAT expression was unchanged in lungs of male fetuses in both control and diabetic groups fed either the olive-oil- or the safflower-oil-supplemented diets when respectively compared with the control and diabetic groups fed the standard diet (Fig. 5B).

ABCA1 expression was unchanged in lungs of female and male fetuses in the diabetic group fed the standard diet when compared with the control group fed the same diet (Fig. 5C). In the control group, ABCA1 expression was unchanged in lungs of female and male fetuses of rats fed either the $6 \%$ olive-oil- or the $6 \%$ safflower-oilsupplemented diets when compared with the control group fed the standard diet (Fig. 5C). However, in the diabetic group, both the $6 \%$ olive-oil- and the $6 \%$ safflower-oil-supplemented diets led to an increase in ABCA1 expression in lungs of female fetuses $(P<0.05)$, although not in lungs of male fetuses when compared with the diabetic groups fed the standard diet (Fig. 5C).

\section{Effect of maternal diets enriched in PPAR ligands on fatty acid composition}

Considering that fatty acid composition modulates function and signaling in cell membranes (Hwang \& Rhee 1999) and the ability of unsaturated fatty acids to activate PPARs (Hihi et al. 2002), we analyzed fatty acid compositions in lungs of fetuses of control and diabetic

Table 2 Fatty acid composition in lungs of fetuses of control and diabetic rats fed with a $6 \%$ olive-oil- or $6 \%$ safflower-oilsupplemented diet during pregnancy. Values represent mean \pm s.E.M. Combined data of one female and one male fetus from each pregnant rat, $n=6$ rats in each experimental group. Two-way ANOVA in conjunction with Bonferroni's test was performed

\begin{tabular}{|c|c|c|c|c|c|c|}
\hline & \multicolumn{3}{|c|}{ Control } & \multicolumn{3}{|c|}{ Diabetic } \\
\hline & Standard diet & $\begin{array}{l}\text { Standard diet } \\
\text { supplemented } \\
\text { with } 6 \% \\
\text { olive oil }\end{array}$ & $\begin{array}{l}\text { Standard diet } \\
\text { supplemented } \\
\text { with } 6 \% \\
\text { safflower oil }\end{array}$ & Standard diet & $\begin{array}{l}\text { Standard diet } \\
\text { supplemented } \\
\text { with } 6 \% \\
\text { olive oil }\end{array}$ & $\begin{array}{l}\text { Standard diet } \\
\text { supplemented } \\
\text { with } 6 \% \\
\text { safflower oil }\end{array}$ \\
\hline C14:0 myristic acid & $1.94 \pm 0.24^{\mathrm{a}}$ & $1.66 \pm 0.33^{a}$ & $2.24 \pm 0.06^{a}$ & $2.06 \pm 0.21^{a}$ & $2.05 \pm 0.09^{a}$ & $1.94 \pm 0.10^{a}$ \\
\hline C15:0 pentadecanoic acid & $1.23 \pm 0.28^{a}$ & $0.38 \pm 0.03^{b}$ & $0.42 \pm 0.05^{b}$ & $0.40 \pm 0.04^{b}$ & $0.49 \pm 0.10^{b}$ & $0.51 \pm 0.05^{b}$ \\
\hline C16:0 palmitic acid & $32.19 \pm 0.56^{a}$ & $31.78 \pm 0.61^{a}$ & $32.48 \pm 0.66^{a}$ & $33.50 \pm 0.18^{a}$ & $31.82 \pm 0.69^{a}$ & $31.52 \pm 0.39^{a}$ \\
\hline C17:0 margaric acid & $0.37 \pm 0.07^{a}$ & $0.18 \pm 0.02^{b}$ & $0.19 \pm 0.02^{b}$ & $0.23 \pm 0.04^{a, b}$ & $0.21 \pm 0.04^{b}$ & $0.23 \pm 0.02^{b}$ \\
\hline C18:0 stearic acid & $11.35 \pm 0.16^{a}$ & $11.69 \pm 0.40^{a}$ & $12.06 \pm 0.31^{a}$ & $11.18 \pm 0.86^{a}$ & $11.63 \pm 0.42^{a}$ & $12.59 \pm 0.31^{a}$ \\
\hline C20:0 arachidic acid & $0.36 \pm 0.03^{a}$ & $0.37 \pm 0.02^{a}$ & $0.38 \pm 0.04^{a}$ & $0.39 \pm 0.03^{a}$ & $0.38 \pm 0.16^{a}$ & $0.39 \pm 0.16^{a}$ \\
\hline C22:0 behenic acid & $1.73 \pm 0.05^{\mathrm{a}}$ & $1.83 \pm 0.07^{\mathrm{a}}$ & $2.03 \pm 0.07^{b}$ & $1.63 \pm 0.20^{a}$ & $1.94 \pm 0.08^{a, b}$ & $2.38 \pm 0.10^{\mathrm{b}}$ \\
\hline C16:1 palmitoleic acid ( $n-7)$ & $6.58 \pm 0.37^{a}$ & $6.31 \pm 0.26^{a}$ & $5.98 \pm 0.29^{a}$ & $5.56 \pm 0.33^{a, b}$ & $4.97 \pm 0.28^{b, c}$ & $4.42 \pm 0.3^{c}$ \\
\hline C18:1 oleic acid $(n-9)$ & $17.33 \pm 0.90^{a}$ & $17.68 \pm 0.32^{a}$ & $15.78 \pm 0.28^{a}$ & $20.19 \pm 3.7^{a}$ & $17.74 \pm 0.03^{a}$ & $15.63 \pm 0.53^{a}$ \\
\hline C20:1 gondoic acid $(n-9)$ & $0.41 \pm 0.05^{a}$ & $0.39 \pm 0.03^{a}$ & $0.30 \pm 0.02^{a}$ & $0.40 \pm 0.05^{a}$ & $0.38 \pm 0.03^{a}$ & $0.34 \pm 0.02^{a}$ \\
\hline C22:1 erucic acid $(n-9)$ & $0.62 \pm 0.07^{a}$ & $0.86 \pm 0.05^{b}$ & $0.91 \pm 0.04^{b}$ & $0.69 \pm 0.08^{a}$ & $0.46 \pm 0.03^{c}$ & $0.57 \pm 0.03^{a}$ \\
\hline C18:2 linoleic acid (n-6) & $4.85 \pm 0.30^{a}$ & $5.09 \pm 0.09^{a}$ & $7.10 \pm 0.42^{b}$ & $5.09 \pm 0.60^{a}$ & $7.74 \pm 0.20^{\mathrm{b}}$ & $8.24 \pm 0.50^{b}$ \\
\hline C20:2 eicosadienoic acid $(n-3 / n-6)$ & $0.56 \pm 0.04^{a}$ & $0.62 \pm 0.07^{a}$ & $0.59 \pm 0.02^{a}$ & $0.53 \pm 0.06^{a}$ & $0.65 \pm 0.03^{a}$ & $0.68 \pm 0.05^{a}$ \\
\hline C20:3 dihomogamma linolenic acid $(n-6)$ & $0.36 \pm 0.04^{a}$ & $0.45 \pm 0.03^{a}$ & $0.54 \pm 0.02^{b}$ & $0.37 \pm 0.05^{a}$ & $0.56 \pm 0.04^{b}$ & $0.63 \pm 0.05^{b}$ \\
\hline C20:4 arachidonic acid $(n-6)$ & $10.30 \pm 0.33^{a}$ & $11.60 \pm 0.17^{b}$ & $11.37 \pm 0.30^{b}$ & $10.49 \pm 0.29^{a}$ & $10.42 \pm 0.42^{a}$ & $11.85 \pm 0.12^{\mathrm{b}}$ \\
\hline C22:5 docosapentaenoic acid (n-3/n-6) & $0.36 \pm 0.06^{a, c}$ & $0.30 \pm 0.04^{a}$ & $0.27+0.03^{a}$ & $0.32 \pm 0.05^{a}$ & $0.49 \pm 0.02^{b}$ & $0.43 \pm 0.04^{b, c}$ \\
\hline C22:6 docosahexaenoic acid $(n-3)$ & $2.69 \pm 0.10^{a}$ & $2.90 \pm 0.10^{a}$ & $2.81 \pm 0.30^{\mathrm{a}}$ & $3.08 \pm 0.38^{a}$ & $2.74 \pm 0.27^{a}$ & $3.19 \pm 0.22^{a}$ \\
\hline
\end{tabular}

Different letters denote significant differences between groups, $P<0.05$.

http://joe.endocrinology-journals.org DOI: $10.1530 /$ JOE-13-0362
(C) 2014 Society for Endocrinology Printed in Great Britain
Published by Bioscientifica Ltd 
rats fed either the $6 \%$ olive-oil- or the $6 \%$ safflower-oilsupplemented diets. No sex-dependent effects were observed on this parameter in the experimental groups evaluated, thus Table 2 shows the combined female and male data. In the animals fed the standard diet, only a decrease in pentadecanoic acid was observed in lungs of fetuses from diabetic rats when compared with the control group $(P<0.01 ;$ Table 2$)$. In lungs of fetuses of control animals, supplementation of the maternal diet with $6 \%$ olive oil led to a decrease in pentadecanoic acid and margaric acid and an increase in erucic acid and arachidonic acid when compared with the control group fed the standard diet $(P<0.05$; Table 2$)$. In lungs of fetuses of control animals, supplementation of the maternal diet with $6 \%$ safflower oil led to a decrease in pentadecanoic acid and margaric acid and to an increase in behenic acid, erucic acid, linoleic acid, dihomogamma linolenic acid, and arachidonic acid when compared with the control group fed the standard diet $(P<0.01$; Table 2$)$. In lungs of fetuses of diabetic animals, supplementation of the diet with $6 \%$ olive oil led to a decrease in erucic acid and to an increase in the PUFAs linoleic acid, dihomogamma linolenic acid, and docosapentaenoic acid when compared with the diabetic group fed the standard diet $(P<0.01$; Table 2). Also, in lungs of fetuses of diabetic animals, supplementation of the maternal diet with $6 \%$ safflower oil led to a decrease in palmitoleic acid and to increases in behenic acid, linoleic acid, dihomogamma linolenic acid, arachidonic acid, and docosapentaenoic acid $(P<0.01$; Table 2).

\section{Discussion}

The findings of this work demonstrate that maternal diabetes leads to an overaccumulation of lipid species and alters PPAR $\alpha$ and PPAR $\gamma$ concentrations in the fetal lung in a sex-dependent manner. Moreover, these studies provide evidence that PPAR activators regulate the expression of lipid transporters and enzymes involved in lipid oxidation which synthesis, which leads to changes in lipid composition and fatty acid content in the fetal lung.

In humans, the lung can be affected by diabetic disease in both the child and the adult, and by maternal diabetes in the fetus (Milla \& Zirbes 2012). Infants born to diabetic mothers are at increased risk of perinatal asphyxia, respiratory distress syndrome, pneumonia, and impaired cardiopulmonary adaptations (Robert et al. 1976, Vela-Huerta et al. 2007, Milla \& Zirbes 2012). Relevant roles for PPARs have been identified in the maturation and regulation of proinflammatory mediators in the lung
(Belvisi \& Hele 2008, Rehan \& Torday 2012). Sex differences in maturation and signaling pathways in lung tissues as well as in lung perinatal diseases have been observed (Carey et al. 2007, Seaborn et al. 2010). Also, poorer perinatal outcome has been reported in male newborns of women with pregestational diabetes (Garcia-Patterson et al. 2011).

In this work, we evaluated a mild diabetic rat model and found increased concentrations of triglycerides in the lungs of female fetuses and of triglycerides and phospholipids in the lungs of male fetuses, indicating that in both sexes, the fetal lung is a target organ that accumulates excessive metabolic substrates in maternal diabetes. There is strong evidence of diabetes-induced changes in lipid metabolism, sex-dependent changes in lipid metabolic pathways, and of the role of estrogens in lipid metabolism (Kautzky-Willer \& Handisurya 2009, Benz et al. 2012, Oosthuyse \& Bosch 2012). Also estrogen-responsive elements are found in PPARs promoters, and estrogens can regulate PPARs expression and activation (Yoon 2009, Oosthuyse \& Bosch 2012). In this regard, we found in this work that maternal diabetes induces a decrease in PPAR $\alpha$ and $\mathrm{PPAR} \gamma$ concentrations only in the lungs of male fetuses. Previous research performed using this experimental model has shown that at term gestation, maternal diabetes increases the fetal weight and the fetal lung weight, induces no changes in fetal lung:fetal weight ratio, and increases markers of an oxidative and proinflammatory environment in fetal lungs and other fetal organs (Jawerbaum \& Capobianco 2011, Kurtz et al. 2012).

Several studies have shown that maternal diabetes leads to increases in the transfer of glucose and other metabolites, which result in excessive metabolic substrates in the fetal circulation and in the fetal liver (Herrera et al. 2006, Martinez et al. 2011b). Possibly, the increased lipids in the lung during maternal diabetes are the result of their efficient uptake from the maternal circulation that sustains the production of surfactant lipids at term gestation (Rooney et al. 1994). Also, we observed a decrease in the expression of the lipid-oxidizing enzymes ACO and CPT1 in lungs of female and male fetuses from diabetic rats. ACO and CPT1 are rate-limiting enzymes in peroxisomal and mitochondrial lipid oxidation, respectively, and clear targets of PPAR $\alpha$ activation in the liver, a signaling pathway relevant in the oxidation of fuels in the fasting state (Desvergne et al. 2006). Besides, PPAR $\alpha$ has been shown to reduce inflammation and vascular leakage in experimental models of acute lung injury, inflammation, and asthma (Becker et al. 2006, Belvisi \& Hele 2008, Schaefer et al. 2008).

Published by Bioscientifica Ltd. 
In this study, no changes in the serum parameters evaluated were found when fetuses from control and diabetic animals received injections of the PPAR agonists $\mathrm{LTB}_{4}$ or $15 \mathrm{dPGJ}_{2}$ compared with their respective groups that received injections of vehicle, showing values similar to those, respectively, found in control and diabetic rats in the untreated groups. On the other hand, these PPAR agonist treatments led to changes in the expression of lipid-oxidizing enzymes in the fetal lung. Indeed, the PPAR $\alpha$ activator $\mathrm{LTB}_{4}$ negatively regulates the expression of ACO and CPT1 in a sex- and diabetic state-dependent manner in the fetal lung, indicating that PPAR $\alpha$ regulates the expression of limiting lipid-oxidizing enzymes in a way opposite to that observed in other adult and developing organs such as the liver (Desvergne et al. 2006, Martinez et al. 2011b, Capobianco et al. 2013). Further research to clarify the nature of these differences should be of value.

On the other hand, we found that in the lungs of male fetuses from diabetic rats, the PPAR $\gamma$ activator $15 \mathrm{dPGJ}_{2}$ positively regulates the expression of ACO and CPT1, and partially restores the expression of these oxidizing enzymes to values observed in control tissues. Activation of PPAR $\gamma$ has been found to ameliorate lung proinflammatory processes in endotoxemic inflammation and prevent asthma induced by nicotine exposure in rat offspring (Liu et al. 2011, Reddy et al. 2012). During fetal lung development, PPAR $\gamma$ regulates the differentiation of lipid-laden fibroblasts, cells that take up circulating lipids, accumulate triglycerides, and transfer them to provide the lipid substrates needed for the production of surfactant lipids in type II alveolar cells (Rehan \& Torday 2012). Previous studies have shown the ability of diets enriched in PUFAs to protect rat neonates from oxygen toxicity (Sosenko et al. 1988), prevent pneumonia in adult mice (Sharma et al. 2013), reduce the occurrence of bronchopulmonary dysplasia in newborn babies (Rudiger et al. 2000), increase PUFA concentrations in neonatal lungs in baboons (Chao et al. 2003), and reduce nitric oxide overproduction in fetal lungs in diabetic rats (Kurtz et al. 2012).

In this work, we found that diets enriched with either $6 \%$ olive oil or $6 \%$ safflower oil increased triglyceride concentrations in the lungs of female fetuses of diabetic rats, and that diets enriched with $6 \%$ olive oil increased phospholipid concentrations in the lungs of male fetuses of diabetic rats when compared with those of diabetic rats fed the standard diet. The concomitant increase in PPAR target genes involved in lipid synthesis (FAS) or transport (FAT) in lungs of female fetuses of diabetic rats fed the $6 \%$ olive-oil- or the $6 \%$ safflower-oil-supplemented diets indicates that this increase may contribute to the accumulation of triglycerides and to providing lipid substrates needed for the production of surfactant lipids in these experimental groups (Rehan \& Torday 2012). The sex differences observed can be explained by the complex effects of estrogens, which induce profound changes in lipid metabolic pathways and regulate PPARs expression, and of androgens, which induce changes in the expression of multiple genes, including several PPAR coactivators and corepressors (Bresson et al. 2010, Benz et al. 2012, Oosthuyse \& Bosch 2012).

On the other hand, we observed a decrease in cholesterol and cholesteryl ester concentrations in the lungs of female fetuses in the diabetic group fed the evaluated diets enriched in PPAR ligands, which may be related to the increased expression of the reverse cholesterol transporter ABCA1 observed in the same experimental groups. Reduced cholesterol concentrations probably increase membrane fluidity and facilitate cell signaling, indicating possible beneficial effects in lungs of fetuses from diabetic rats, a point that deserves further research. In addition, it should be noted that although the unsaturated fatty acids provided by the oil-supplemented diets evaluated can both activate PPARs and serve as substrates for the synthesis of other PPAR activators, endogenous PPAR ligands can also have PPAR-independent effects (Luconi et al. 2010, Wahli \& Michalik 2012). Also, although only minor changes were detected in fatty acid composition in the fetal lungs of the diabetic group when compared with the controls, an important increase in PUFAs was found in the diabetic group fed the $6 \%$ oliveoil- and the 6\% safflower-oil-supplemented diets when compared with the diabetic group fed the standard diet.

Previous studies have shown that supplementation of diets with PUFAs increases lung concentrations of PUFAs, indicating their efficient transfer from the maternal diet to the lung (Sosenko et al. 1991, Chao et al. 2003). Our results indicate that these changes, which can help to protect the lung function during the perinatal period, can be achieved in maternal diabetes as efficiently as in the control mothers. The $6 \%$ safflower-oil-supplemented diet provides linoleic acid, an essential fatty acid that is the substrate for the production of other $n$ - 6 PUFAs that are increased in lungs of fetuses of the rats fed both diets enriched in unsaturated fatty acids. Interestingly, although the $6 \%$ olive-oil-supplemented diet is mostly enriched in oleic acid, which cannot be metabolized into PUFAs in animals, both $n-6$ and $n$-3 PUFAs are increased in lungs of fetuses of rats fed this supplemented diet.

Published by Bioscientifica Ltd. 
Thus, possibly, an antioxidant function of the olive-oilsupplemented diet, which deserves to be further studied and may be exerted both through its high content of polyphenols and through the antioxidant effect of PPARs activation, may help to preserve PUFAs in the fetal lung. This may constitute a relevant function in diabetic pregnancies, in which the loss of PUFAs due to peroxidation is a relevant problem that leads to the loss of many bioactive lipids, including those that activate PPARs (Jawerbaum \& Gonzalez 2006, Negre-Salvayre et al. 2010).

In conclusion, increased lipid content and few changes in fatty acid composition are observed in the fetal lung at term in the mild diabetic rat model evaluated. In vivo administration of PPAR ligands led to changes in lipid content, in the expression of lipid transporters and enzymes involved in lipid oxidation and synthesis, and in the proportion of PUFAs in lungs of fetuses of diabetic rats, possibly providing a local activation of PPARs that may help the lungs to accomplish their complex functions in the perinatal period in maternal diabetes.

\section{Declaration of interest}

The authors declare that there is no conflict of interest that could be perceived as prejudicing the impartiality of the research reported.

\section{Funding}

This work was supported by the Agencia Nacional de Promoción Científica y Tecnológica de Argentina (grant number PICT 2010-00034) and by the Consejo Nacional de Investigaciones Científicas y Técnicas (CONICET; grant number PIP 11220100100002). E C, N M, M B M, and A J are research members of CONICET.

Acknowledgements

The authors thank Vet. Marcela Márquez and Tech. Enzo Cuba for the valuable help with animal handling.

\section{References}

Ali S \& Dornhorst A 2011 Diabetes in pregnancy: health risks and management. Postgraduate Medical Journal 87 417-427. (doi:10.1136/ pgmj.2010.109157)

Becker J, Delayre-Orthez C, Frossard N \& Pons F 2006 Regulation of inflammation by PPARs: a future approach to treat lung inflammatory diseases? Fundamental \& Clinical Pharmacology 20 429-447. (doi:10.1111/j.1472-8206.2006.00425.x)

Belvisi MG \& Hele DJ 2008 Peroxisome proliferator-activated receptors as novel targets in lung disease. Chest 134 152-157. (doi:10.1378/chest. 08-0019)

Benz V, Kintscher U \& Foryst-Ludwig A 2012 Sex-specific differences in type 2 diabetes mellitus and dyslipidemia therapy: PPAR agonists. Handbook of Experimental Pharmacology 214 387-410. (doi:10.1007) 978-3-642-30726-3_18)
Bourbon JR \& Farrell PM 1985 Fetal lung development in the diabetic pregnancy. Pediatric Research 19 253-267. (doi:10.1203/00006450198503000-00001)

Bresson E, Seaborn T, Cote M, Cormier G, Provost PR, Piedboeuf B \& Tremblay Y 2010 Gene expression profile of androgen modulated genes in the murine fetal developing lung. Reproductive Biology and Endocrinology 8 2. (doi:10.1186/1477-7827-8-2)

Capobianco E, Jawerbaum A, Romanini MC, White V, Pustovrh C, Higa R, Martinez N, Mugnaini MT, Sonez C \& Gonzalez E 2005 15-Deoxy$\Delta 12,14$-prostaglandin $\mathrm{J} 2$ and peroxisome proliferator-activated receptor $\gamma(\operatorname{PPAR} \gamma)$ levels in term placental tissues from control and diabetic rats: modulatory effects of a PPAR $\gamma$ agonist on nitridergic and lipid placental metabolism. Reproduction, Fertility, and Development 17 423-433. (doi:10.1071/RD04067)

Capobianco E, Martinez N, Fornes D, Higa R, Marco ID, Basualdo MN, Faingold MC \& Jawerbaum A 2013 PPAR activation as a regulator of lipid metabolism, nitric oxide production and lipid peroxidation in the placenta from type 2 diabetic patients. Molecular and Cellular Endocrinology 377 7-15. (doi:10.1016/j.mce.2013.06.027)

Careaga VP, Muniain C \& Maier MS 2013 Fatty acid composition of the edible sea cucumber Athyonidium chilensis. Natural Product Research 27 639-647. (doi:10.1080/14786419.2012.686909)

Carey MA, Card JW, Voltz JW, Arbes SJ Jr, Germolec DR, Korach KS \& Zeldin DC 2007 It's all about sex: gender, lung development and lung disease. Trends in Endocrinology and Metabolism 18 308-313. (doi:10.1016/j.tem. 2007.08.003)

Chao AC, Ziadeh BI, Diau GY, Wijendran V, Sarkadi-Nagy E, Hsieh AT, Nathanielsz PW \& Brenna JT 2003 Influence of dietary long-chain PUFA on premature baboon lung FA and dipalmitoyl PC composition. Lipids 38 425-429. (doi:10.1007/s11745-003-1079-8)

Chen H, Jackson S, Doro M \& McGowan S 1998 Perinatal expression of genes that may participate in lipid metabolism by lipid-laden lung fibroblasts. Journal of Lipid Research 39 2483-2492.

Cheng L, Ding G, Qin Q, Xiao Y, Woods D, Chen YE \& Yang Q 2004 Peroxisome proliferator-activated receptor $\delta$ activates fatty acid oxidation in cultured neonatal and adult cardiomyocytes. Biochemical and Biophysical Research Communications 313 277-286. (doi:10.1016/ j.bbrc.2003.11.127)

Desvergne B, Michalik L \& Wahli W 2006 Transcriptional regulation of metabolism. Physiological Reviews 86 465-514. (doi:10.1152/physrev. 00025.2005)

Garcia-Patterson A, Aulinas A, Sojo L, Ginovart G, Adelantado JM, de Leiva A \& Corcoy R 2011 Poorer perinatal outcome in male newborns of women with pregestational diabetes mellitus. Diabetic Medicine 28 436-439. (doi:10.1111/j.1464-5491.2011.03227.x)

Herrera E \& Ortega-Senovilla H 2010 Disturbances in lipid metabolism in diabetic pregnancy - are these the cause of the problem? Best Practice \& Research. Clinical Endocrinology and Metabolism 24 515-525. (doi:10. 1016/j.beem.2010.05.006)

Herrera E, Amusquivar E, Lopez-Soldado I \& Ortega H 2006 Maternal lipid metabolism and placental lipid transfer. Hormone Research 65(Suppl 3) 59-64. (doi:10.1159/000091507)

Higa R \& Jawerbaum A 2013 Intrauterine effects of impaired lipid homeostasis in pregnancy diseases. Current Medicinal Chemistry 20 2338-2350. (doi:10.2174/0929867311320180005)

Hihi AK, Michalik L \& Wahli W 2002 PPARs: transcriptional effectors of fatty acids and their derivatives. Cellular and Molecular Life Sciences 59 790-798. (doi:10.1007/s00018-002-8467-x)

Hwang D \& Rhee SH 1999 Receptor-mediated signaling pathways: potential targets of modulation by dietary fatty acids. American Journal of Clinical Nutrition 70 545-556.

Jawerbaum A \& Capobianco E 2011 Review: Effects of PPAR activation in the placenta and the fetus: implications in maternal diabetes. Placenta 32(Suppl 2) S212-S217. (doi:10.1016/j.placenta.2010.12.002) 
Jawerbaum A \& Gonzalez E 2006 Diabetic pregnancies: the challenge of developing in a pro-inflammatory environment. Current Medicinal Chemistry 13 2127-2138. (doi:10.2174/092986706777935302)

Jawerbaum A \& White V 2010 Animal models in diabetes and pregnancy. Endocrine Reviews 31 680-701. (doi:10.1210/er.2009-0038)

Jawerbaum A, Capobianco E, Pustovrh C, White V, Baier M, Salzberg S, Pesaresi M \& Gonzalez E 2004 Influence of peroxisome proliferatoractivated receptor $\gamma$ activation by its endogenous ligand 15-deoxy $\Delta 12,14$ prostaglandin $\mathrm{J} 2$ on nitric oxide production in term placental tissues from diabetic women. Molecular Human Reproduction 10 671-676. (doi:10.1093/molehr/gah090)

Kautzky-Willer A \& Handisurya A 2009 Metabolic diseases and associated complications: sex and gender matter!. European Journal of Clinical Investigation 39 631-648. (doi:10.1111/j.1365-2362.2009.02161.x)

Kobayashi M, Gouda K, Chisaki I, Ochiai M, Itagaki S \& Iseki K 2011 Regulation mechanism of ABCA1 expression by statins in hepatocytes. European Journal of Pharmacology 662 9-14. (doi:10.1016/j.ejphar.2011. 04.043)

Koskinen A, Laiho A, Lukkarinen H, Kaapa P \& Soukka H 2010 Maternal hyperglycemia modifies extracellular matrix signaling pathways in neonatal rat lung. Neonatology 98 387-396. (doi:10.1159/000317010)

Koskinen A, Lukkarinen H, Moritz N, Aho H, Kaapa P \& Soukka H 2012 Fetal hyperglycemia alters lung structural development in neonatal rat. Pediatric Pulmonology 47 275-282. (doi:10.1002/ppul.21541)

Kurtz M, Martinez N, Capobianco E, Higa R, Fornes D, White V \& Jawerbaum A 2012 Increased nitric oxide production and genderdependent changes in PPAR $\alpha$ expression and signaling in the fetal lung from diabetic rats. Molecular and Cellular Endocrinology 362 120-127. (doi:10.1016/j.mce.2012.05.018)

Lappas M, Hiden U, Desoye G, Froehlich J, Mouzon SH \& Jawerbaum A 2011 The role of oxidative stress in the pathophysiology of gestational diabetes mellitus. Antioxidants and Redox Signaling 15 3061-3100. (doi:10.1089/ars.2010.3765)

Lefebvre P, Chinetti G, Fruchart JC \& Staels B 2006 Sorting out the roles of PPAR $\alpha$ in energy metabolism and vascular homeostasis. Journal of Clinical Investigation 116 571-580. (doi:10.1172/JCI27989)

Lillycrop KA, Phillips ES, Jackson AA, Hanson MA \& Burdge GC 2005 Dietary protein restriction of pregnant rats induces and folic acid supplementation prevents epigenetic modification of hepatic gene expression in the offspring. Journal of Nutrition 135 1382-1386.

Liu J, Sakurai R, O'Roark EM, Kenyon NJ, Torday JS \& Rehan VK 2011 $\operatorname{PPAR} \gamma$ agonist rosiglitazone prevents perinatal nicotine exposureinduced asthma in rat offspring. American Journal of Physiology. Lung Cellular and Molecular Physiology 300 L710-L717. (doi:10.1152/ajplung. 00337.2010)

Luconi M, Cantini G \& Serio M 2010 Peroxisome proliferator-activated receptor $\gamma(\operatorname{PPAR} \gamma)$ : is the genomic activity the only answer? Steroids 75 585-594. (doi:10.1016/j.steroids.2009.10.012)

Martinez N, Kurtz M, Capobianco E, Higa R, White V \& Jawerbaum A $2011 a$ $\operatorname{PPAR} \alpha$ agonists regulate lipid metabolism and nitric oxide production and prevent placental overgrowth in term placentas from diabetic rats. Journal of Molecular Endocrinology 47 1-12. (doi:10.1530/JME-10-0173)

Martinez N, White V, Kurtz M, Higa R, Capobianco E \& Jawerbaum A 2011b Activation of the nuclear receptor PPAR $\alpha$ regulates lipid metabolism in foetal liver from diabetic rats: implications in diabetes-induced foetal overgrowth. Diabetes/Metabolism Research and Reviews 27 35-46. (doi:10.1002/dmrr.1151)

Martinez N, Sosa M, Higa R, Fornes D, Capobianco E \& Jawerbaum A 2012 Dietary treatments enriched in olive and safflower oils regulate seric and placental matrix metalloproteinases in maternal diabetes. Placenta 33 8-16. (doi:10.1016/j.placenta.2011.10.015)

Milla CE \& Zirbes J 2012 Pulmonary complications of endocrine and metabolic disorders. Paediatric Respiratory Reviews 13 23-28. (doi:10.1016/j.prrv.2011.01.004)

Narala VR, Adapala RK, Suresh MV, Brock TG, Peters-Golden M \& Reddy RC 2010 Leukotriene B4 is a physiologically relevant endogenous peroxisome proliferator-activated receptor- $\alpha$ agonist. Journal of Biological Chemistry 285 22067-22074. (doi:10.1074/jbc.M109.085118) Negre-Salvayre A, Auge N, Ayala V, Basaga H, Boada J, Brenke R, Chapple S, Cohen G, Feher J, Grune T et al. 2010 Pathological aspects of lipid peroxidation. Free Radical Research 44 1125-1171. (doi:10.3109/ 10715762.2010.498478)

Oosthuyse T \& Bosch AN 2012 Oestrogen's regulation of fat metabolism during exercise and gender specific effects. Current Opinion in Pharmacology 12 363-371. (doi:10.1016/j.coph.2012.02.008)

Piper JM 2002 Lung maturation in diabetes in pregnancy: if and when to test. Seminars in Perinatology 26 206-209. (doi:10.1053/sper.2002. 33969)

Pustovrh MC, Capobianco E, Martinez N, Higa R, White V \& Jawerbaum A $2009 \mathrm{MMP} / \mathrm{TIMP}$ balance is modulated in vitro by $15 \mathrm{dPGJ}_{2}$ in fetuses and placentas from diabetic rats. European Journal of Clinical Investigation 39 1082-1090. (doi:10.1111/j.1365-2362.2009.02200.x)

Reddy AT, Lakshmi SP, Kleinhenz JM, Sutliff RL, Hart CM \& Reddy RC 2012 Endothelial cell peroxisome proliferator-activated receptor $\gamma$ reduces endotoxemic pulmonary inflammation and injury. Journal of Immunology 189 5411-5420. (doi:10.4049/jimmunol.1201487)

Rehan VK \& Torday JS 2012 PPAR $\gamma$ signaling mediates the evolution, development, homeostasis, and repair of the lung. PPAR Research 2012 289867. (doi:10.1155/2012/289867)

Robert MF, Neff RK, Hubbell JP, Taeusch HW \& Avery ME 1976 Association between maternal diabetes and the respiratory-distress syndrome in the newborn. New England Journal of Medicine 294 357-360. (doi:10.1056/ NEJM197602122940702)

Rooney SA, Young SL \& Mendelson CR 1994 Molecular and cellular processing of lung surfactant. FASEB Journal 8 957-967.

Rudiger M, von Baehr A, Haupt R, Wauer RR \& Rustow B 2000 Preterm infants with high polyunsaturated fatty acid and plasmalogen content in tracheal aspirates develop bronchopulmonary dysplasia less often. Critical Care Medicine 28 1572-1577. (doi:10.1097/00003246200005000-00052)

Salas A, Noe V, Ciudad CJ, Romero MM, Remesar X \& Esteve M 2007 Shortterm oleoyl-estrone treatment affects capacity to manage lipids in rat adipose tissue. BMC Genomics 8 292. (doi:10.1186/1471-2164-8-292)

Schaefer MB, Pose A, Ott J, Hecker M, Behnk A, Schulz R, Weissmann N, Gunther A, Seeger W \& Mayer K 2008 Peroxisome proliferator-activated receptor- $\alpha$ reduces inflammation and vascular leakage in a murine model of acute lung injury. European Respiratory Journal 32 1344-1353. (doi:10.1183/09031936.00035808)

Scher JU \& Pillinger MH 2005 15d-PGJ 2 : the anti-inflammatory prostaglandin? Clinical Immunology 114 100-109. (doi:10.1016/j.clim.2004. 09.008)

Seaborn T, Simard M, Provost PR, Piedboeuf B \& Tremblay Y 2010 Sex hormone metabolism in lung development and maturation. Trends in Endocrinology and Metabolism 21 729-738. (doi:10.1016/ j.tem.2010.09.001)

Sharma S, Chhibber S \& Mohan H 2013 Dietary supplementation with $\omega-3$ polyunsaturated fatty acids ameliorates acute pneumonia induced by Klebsiella pneumoniae in BALB/c mice. Canadian Journal of Microbiology 59 503-510. (doi:10.1139/cjm-2012-0521)

Simeoni U \& Barker DJ 2009 Offspring of diabetic pregnancy: long-term outcomes. Seminars in Fetal \& Neonatal Medicine 14 119-124. (doi:10.1016/j.siny.2009.01.002)

Sosenko IR, Innis SM \& Frank L 1988 Polyunsaturated fatty acids and protection of newborn rats from oxygen toxicity. Journal of Pediatrics 112 630-637. (doi:10.1016/S0022-3476(88)80186-0)

Sosenko IR, Innis SM \& Frank L 1991 Intralipid increases lung polyunsaturated fatty acids and protects newborn rats from oxygen toxicity. Pediatric Research 30 413-417. (doi:10.1203/00006450199111000-00004)

Trevino-Alanis M, Ventura-Juarez J, Hernandez-Pinero J, Nevarez-Garza A, Quintanar-Stephano A \& Gonzalez-Pina A 2009 Delayed lung maturation of foetus of diabetic mother rats develop with a diminish, 
but without changes in the proportion of type I and II pneumocytes, and decreased expression of protein D-associated surfactant factor. Anatomia, Histologia, Embryologia 38 169-176. (doi:10.1111/ j.1439-0264.2008.00902.x)

Vela-Huerta M, Aguilera-Lopez A, Alarcon-Santos S, Amador N, Aldana-Valenzuela C \& Heredia A 2007 Cardiopulmonary adaptation in large for gestational age infants of diabetic and nondiabetic mothers. Acta Paediatrica 96 1303-1307. (doi:10.1111/j.1651-2227. 2007.00414.x)

Wagner MC, Yeligar SM, Brown LA \& Michael Hart C 2012 PPAR $\gamma$ ligands regulate NADPH oxidase, eNOS, and barrier function in the lung following chronic alcohol ingestion. Alcoholism, Clinical and Experimental Research 36 197-206. (doi:10.1111/j.1530-0277.2011.01599.x)

Wahli W \& Michalik L 2012 PPARs at the crossroads of lipid signaling and inflammation. Trends in Endocrinology and Metabolism 23 351-363. (doi:10.1016/j.tem.2012.05.001)

Weindling AM 2009 Offspring of diabetic pregnancy: short-term outcomes. Seminars in Fetal and Neonatal Medicine 14 111-118. (doi:10.1016/j.siny. 2008.11.007)

Yoon M 2009 The role of PPAR $\alpha$ in lipid metabolism and obesity: focusing on the effects of estrogen on PPAR $\alpha$ actions. Pharmacological Research 60 151-159. (doi:10.1016/j.phrs.2009.02.004)

Received in final form 13 December 2013

Accepted 2 January 2014

Accepted Preprint published online 3 January 2014
Published by Bioscientifica Ltd. 